\title{
Intestinal Polyposis Syndrome
}

National Cancer Institute

\section{Source}

National Cancer Institute. Intestinal Polyposis Syndrome. NCI Thesaurus. Code C155954.

A syndrome associated with the development of multiple polyps throughout the intestine. It includes familial adenomatous polyposis, hamartomatous polyposis syndromes, and other rare polyposis syndromes. 